\title{
A Pragmatist Approach to the Proper Scope of Government
}

\author{
Comment
}

by

FRITZ W. SCHARPF

Given the enormous historical and contemporary diversity and variability of legitimate governance institutions, the search for general theories or normative principles defining "the proper scope of government" might appear as a curious academic exercise in which intellectual brilliance could be displayed in interesting disputes without any fear of ever reaching conclusions. At the same time, however, the last century has demonstrated the apparent effectiveness of ideologies purporting to define the proper location of the boundary between the power of the state and the liberties of nonstate actors. Totalitarian ideologies seemed to legitimate the subordination of the individual and of the institutions of civil society to unfettered state control, whereas libertarian ideologies are used to justify the subordination of the individual and of the institutions of civil society to the pressures of unfettered international markets. Of course, ideological lineage need not imply effective chains of causation, let alone culpability in the criminal-law sense. In that sense, Marx may be no more accountable for the horrors of the Gulag than Hayek is responsible for the Indonesian sweatshops of European multinationals or for the economic disasters unleashed by global currency speculation.

But however difficult it may be to empirically demonstrate the causal power of ideas, Ideologiekritik remains one of the socially more useful academic exercises in the field of normative political theory. For one thing, by clarifying, analyzing, and criticizing the assumptions, implications, and internal consistency of a dominant ideology, it may help to separate interest-based from conviction-based political support in the public debates over specific policy choices that are supposedly justified by reference to a particular system of normative political beliefs. Under the conditions of interest-group vetoes and media politics, it is true, that may seem a weak hope. There is, however, a second channel through which purely academic discourses may have an effect: they may influence the outcomes reached in nonmajoritarian institutions that are required to provide reasons for their policy choices. This influence may be affirmative or critical, strengthening or weakening the arguments supporting given policies. Thus, the worldwide deregulation movement had its origin in the neoliberal critique of market-failure arguments used to 
justify monopolistic solutions, and it achieved its first success in the American courts. Similarly, the liberalization, deregulation, and privatization of wide ranges of public utilities in Europe was largely shaped by liberal (and mainly German) competition lawyers and their ability to persuade the Commission and the European Court of Justice of the beneficial economic effects and the normative rightness of a regime of undistorted competition. In its main thrust, Jack KNIGHT's [2001] paper may be read as an ideology-critical reexamination of the theoretical foundations of this libertarian orientation.

Committed to a pragmatist approach, Knight quickly dismisses the possibility of formulating affirmative answers to the question implied by the title of this conference: Given the increasing diversity, volatility, and horizontal and vertical interdependence of the factors affecting human choices, it makes no sense to search for "a clear and distinct boundary for the scope of government" (p. 29) at the level of general theory. Instead, this search must be experimental, and experiential judgments are likely to differ in time and place. Nevertheless (and going beyond Dewey's more skeptical position), Knight claims that there are generally applicable "substantive" and "procedural" criteria of what constitutes "good" institutional solutions under varying circumstances.

On the substantive side, the most abstract criterion refers to the problem-solving capacity of institutions - which "is to be determined by those who are involved in the interaction in accordance with their own interests" (p. 33). However, the subjectivist implications of this formulation are sidestepped by redefining the criterion in an information-theoretic sense: "what institution will best help [the actors] to acquire the information necessary to achieve their individual and collective goals?" (p. 33) Classifying institutional solutions in two dimensions, centralization of decisions and reliance on the authority of the state, the substantive conclusion is that governmental solutions should only be selected when the relevant information about individual interests and ideas can easily be aggregated and processed in centralized government decisions. That may not be true of many of the functions presently performed by governments. For Knight, however, that is only half of the story.

The other half is captured by his "procedural" criterion requiring the "free and equal participation of all individuals" (p. 36) in order to meet the (again, information-theoretic) requirement of "free and equal consideration of all points of view" (p. 36). On this score, Knight examines and compares the justification of (an idealized version of) centralized deliberative democracy with Hayek's justification of decentralized market choices and Posner's justification of decentralized commonlaw adjudication. All three institutional solutions, he explains, can only be justified if the free-and-equal-participation condition is assumed. Since equal power cannot be presupposed, the extent to which this condition can be satisfied depends on rules of the game protecting equal participation. But effective protection is unlikely to be provided by informal mechanisms; it depends on formal laws and government enforcement. Since neither Hayek nor Posner is willing to provide for specific institutional safeguards to assure the satisfaction of this condition, Knight 
finds their justifications insufficient. His conclusion: Even if according to the "substantive" criterion the primary problem-solving functions of government are defined narrowly, the secondary "procedural" role of the state in safeguarding equal participation in decentralized institutions must be fairly extensive.

From a debating-points perspective, the article is successful because it adopts the information-theoretic premises of Hayekian liberalism and shows that these premises cannot support Hayekian conclusions about the proper scope of government in the absence of effective institutional arrangements assuring that decentralized decisions will be based on all relevant information. From a more inclusive perspective, however, these premises also appear as the major weakness of the article. By focusing on the problems of accessing, aggregating, and processing (local) information, Knight tends to ignore the "interest" dimension of social and political interactions - he seems to assume a world in which only games of pure coordination are being played, ignoring the fact that even under conditions of equal participation and "complete information" the actors may find themselves locked in mortal conflict, rather than engaged in mutually beneficial "problem solving." If he had given the interest dimension equal weight, his "substantive" criteria would also have had to address the question of which types of conflicts of interest could be handled by decentralized institutional arrangements, which (think of U.S. racial segregation in the 1950s) could only be resolved by centralized state authority, and for which the optimal solution might be multilevel governance structures combining centralized as well as decentralized elements.

This objection does not detract from Knight's critique of Hayekian liberalism, which is based on the same exclusive focus on the information dimension, and also seems to assume that the underlying constellations of interest resemble games of pure coordination or, at the most, battle-of-the-sexes games. Hayek's intuition of a "spontaneous order" was formulated before the fundamental concept of the Nash equilibrium was discovered. He never bothered to update his social philosophy to take account of the possibility that, under a wide variety of constellations of interest, decentralized interactions might "lock in" on socially harmful equilibria (say, under conditions of the prisoner's-dilemma or the deadlock game) or on highly asymmetric and exploitative equilibria (say, under conditions of chicken or Rambo games). If these possibilities are taken into account, there is no theoretical justification for assuming that the "spontaneous order" resulting from decentralized interactions should generally have socially beneficial characteristics.

But while a reference to John Nash would have made Knight's objections to Hayek more elegantly compelling, it would not have strengthened his own conclusions. The state may indeed be necessary for imposing and enforcing proper rules of the game on decentralized interactions - but how can we be sure that the powers of the state will only be used for these beneficial purposes, and what justifies the hope that they will be sufficient for these purposes?

In response to the first question, KNIGHT [2001] seems to refer affirmatively to the ideal of deliberative democracy in which "ideas are assessed in terms of their quality, and not in terms of some arbitrary factor ..." (p. 36). But in order to sup- 
port his conclusion, he would have to rely on the Habermasian equation of political interactions with truth-oriented discourses - in which interest-oriented strategies are not playing any role. When that (unrealistic) assumption is not made, Knight's more "extensive role for the state" is open to all the objections that public-choice theory has raised against the rule of self-interested majorities and, more generally, against the equation of state action with the pursuit of the public interest. In that case, the rent-seeking and principal-agent problems of state action would need to be taken as seriously as the deficiencies of Hayekian decentralization - with the consequence that a "pragmatic" assessment of the pros and cons of governmental action would become indeterminate.

To the extent that Knight addresses these issues, his affirmative remedy seems to be institutional arrangements that will weaken the capacity of governments through the separation of powers, federalism, and the establishment of "polycentric governance systems." This then raises the second question of whether governments so weakened would still have the capacity to impose and enforce proper rules of the game on powerful nongovernmental actors enjoying the freedom of unfettered movement and interaction in the global economy.

In conclusion, Knight's paper is convincing in its criticism of the procedural foundations of Hayekian liberalism. But it seems strangely unconcerned about the assumptions underlying its own affirmative propositions.

\section{References}

KNIGHT, J. [2001], “A Pragmatist Approach to the Proper Scope of Government," Journal of Institutional and Theoretical Economics, 157, 28-48.

Fritz W. Scharpf

Max-Planck-Institut für Gesellschaftsforschung

Paulstr. 3

50676 Köln

Germany

E-mail: scharpf@mpi-fg-koeln.mpg.de 